\title{
Novel Cell-Based Assay to Investigate Monoacylglycerol Acyltransferase 2 Inhibitory Activity Using HIEC-6 Cell Line
}

\author{
Yeshvanthi Singh, Akshay Datey, Dipshikha Chakravortty, and Ajay W. Tumaney*
}

Cite This: ACS Omega 2021, 6, 1732-1740

Read Online

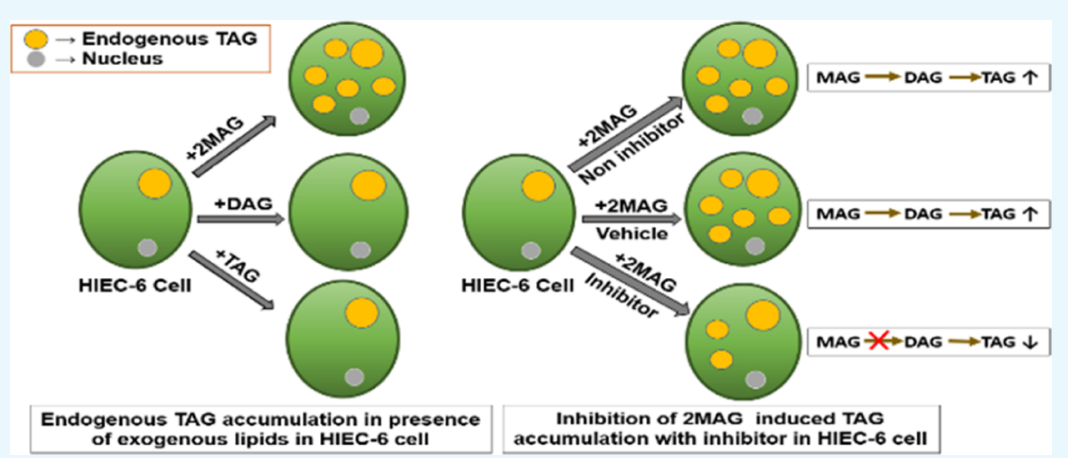

ABSTRACT: The dietary triacylglycerol (TAG) gets absorbed and accumulated in the body through the monoacylglycerol (MAG) pathway, which plays a major role in obesity and related disorders. The main enzyme of this pathway, monoacylglycerol acyltransferase 2 (MGAT2), is considered as a potential target for developing antiobesity compounds. Hence, there is a need for in vitro cell-based assays for screening the potential leads for MGAT2 inhibitors. Because of synthetic inhibitor's side effects, there is an increased interest in natural extracts as potential leads. Hence, we have optimized a 2-MAG-induced TAG accumulation inhibitory cell-based assay to screen natural extracts using the HIEC-6 cell line. A concentration-dependent TAG accumulation was observed when the HIEC-6 cells were fed with exogenous 2-MAG. The TAG accumulation was confirmed by in situ BODIPY staining and was quantified. However, no TAG accumulation was seen when the cells were fed with exogenous DAG or TAG, suggesting MGAT2mediated MAG uptake and its conversion to TAG. We demonstrated the utility of this assay by screening five different plant-based aqueous extracts. These extracts showed various inhibition levels (25\% to 30\%) of 2-MAG-induced TAG accumulation in the HIEC6. The MGAT2 inhibitory potential of these extracts was confirmed by an in vitro MGAT2 assay. This cell-based assay adds a new methodology for screening, developing, and evaluating MGAT2 inhibitors for addressing obesity and related disorders.

\section{INTRODUCTION}

Obesity is defined as excess storage of fat in the body due to the variation between energy intake and energy expenditure. The modern diet and sedentary lifestyle are important factors that have a link with obesity. ${ }^{1}$ The dietary lipids are digested by pancreatic lipase and are hydrolyzed to monoacylglycerol (MAG) and free fatty acids. The MAG gets absorbed in the intestine and re-esterified back to triacylglycerol (TAG) by the MAG pathway.

This re-esterification is significant and is carried out by two major enzymes: monoacylglycerol acyltransferase (MGAT) and diacylglycerol acyltransferase (DGAT). ${ }^{2}$ The esterified TAG gets into circulation and is accumulated in the body, which under certain conditions leads to obesity. Three isoforms of MGAT, namely, MGAT1, MGAT2, and MGAT3, have been reported. ${ }^{3,4}$ In both mice and humans, MGAT2 is highly expressed in the small intestine, and the inhibition of MGAT2 can be a potential target to develop antiobesity drug. ${ }^{2,5,6}$ Hence, in recent years, MGAT2 is studied as a critical target for addressing morbid obesity and its associated comorbidities such as type- 2 diabetes, cardiovascular diseases, and osteoarthritis.?

Many synthetic inhibitors for MGAT2 have been reported, but detailed pharmacological inhibition characteristics have not been performed in most of these studies. However, Okuma et al. studied a novel MGAT2 inhibitor-JTP103237 and evaluated its pharmacological profiling. The MGAT2 inhibitor would be useful in obesity by restricting excessive fat intake. ${ }^{8}$ Synthetic MGAT2 inhibitors that block fat absorption are mostly patented but not commercialized because of low gastrointestinal (GI) tolerability and safety considerations. MGAT2 inhibition with natural plant extracts alleviates

Received: December 7, 2020

Accepted: December 23, 2020

Published: January 6, 2021 


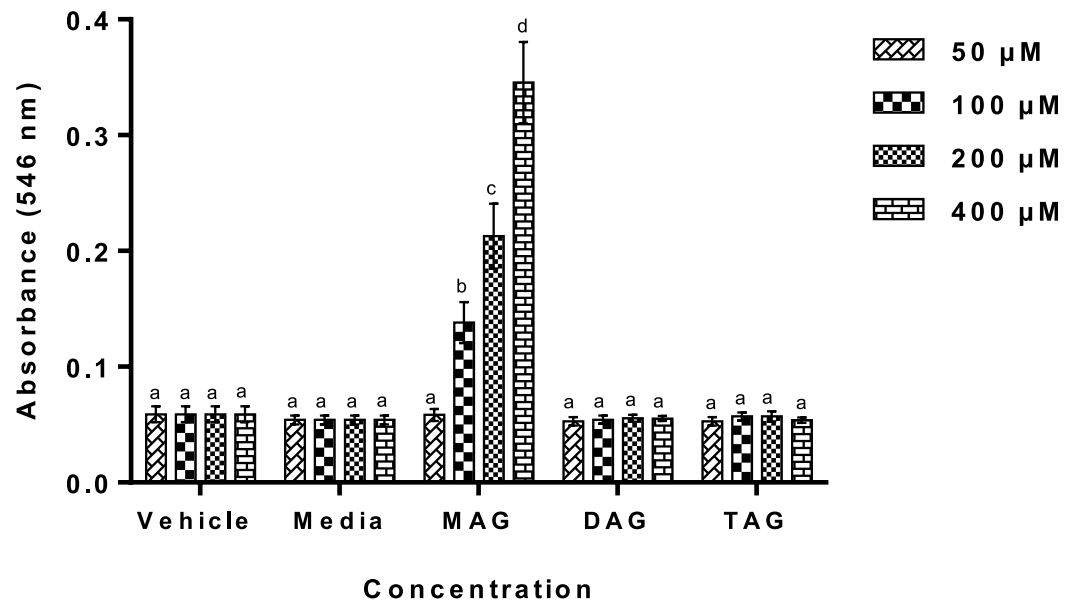

Figure 1. Effect of exogenous 2-MAG, DAG, and TAG on TAG formation in HIEC-6 cells at 50, 100, 200, and $400 \mu$ M concentration. TAG levels were determined using a triglyceride assay kit as described in the Materials and Methods section, and the absorbance was read using a multiwell plate reader. For each time point, the means with range of absorbance from three independent experiments are presented. Media control-without addition of any exogenous acylglycerol. Vehicle control-ethanol at $0.5 \%$ final concentration. Values are means \pm SD $(n=3)$ of data from two separate experiments with three replicates. Mean values with the same superscript letters are not significantly different, whereas those with different superscript letters differ significantly $(P<0.05)$ as analyzed by Duncan's multiple range tests.
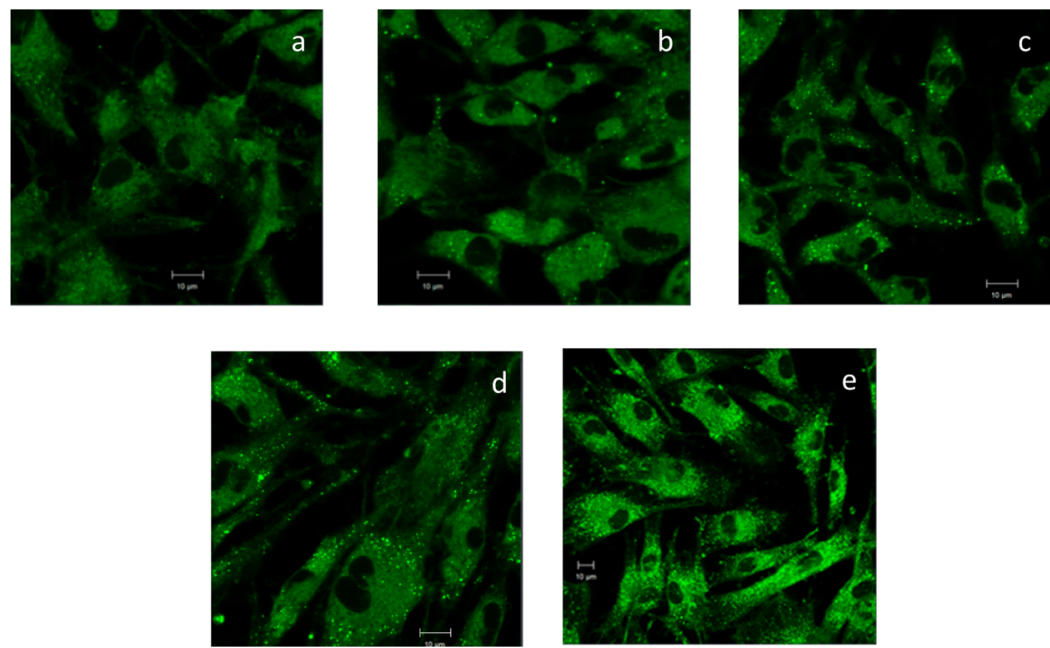

Figure 2. Confocal microscopy of TAG induction using 2-MAG in HIEC-6 cells. (a) Media control, (b) Vehicle control, (c) $100 \mu \mathrm{M} 2-\mathrm{MAG}$, (d) $200 \mu \mathrm{M}$ 2-MAG, and (e) $400 \mu \mathrm{M}$ 2-MAG. BODIPY staining of HIEC-6 cells was performed as given in the Materials and Methods section.

commercial synthetic drugs' side effects to control obesity and is considered to be the safest approach. This therapeutic approach for MGAT2 inhibition provides superior efficacy concerning GI tolerability. ${ }^{9}$ Thus, MGAT2 is a suitable target, and plant-based extracts are appropriate for treating obesity and other metabolic disorders.

Several attempts have been made, such as overexpression of the enzyme, inhibition by synthetic inhibitors, and isotopelabeled substrate with high-resolution LC/MS, to devise assays to screen for MGAT2 inhibitors. However, these assays are unwieldy, sophisticated, and time-consuming. ${ }^{10,11}$ Hence, there is a need for an effective, economic, and efficient assay strategy based on a simple substrate and efficient screening system. The presence of MGAT2 enzyme activity in the intestine justifies a suitable cell line system, preferably with enterocytes such as Caco-2 or HIEC-6. ${ }^{12}$ Moreover, according to various studies, for MGAT2 enzyme activity, the application of HIEC- 6 cell line models is the most suitable than conventional cell lines such as Caco-2. ${ }^{13}$
Thus, the present study aimed to develop an effective cellbased assay to screen various plant extracts for MGAT2 inhibition. The HIEC-6 cell line-based assay was optimized to assess inhibition of 2-MAG-induced TAG accumulation in the cells. Finally, this assay's utility was demonstrated by screening five different plant-based aqueous extracts in this cell-based assay. The MGAT2 inhibitory potential of these extracts was confirmed by an in vitro MGAT2 assay using mouse intestinal microsomes. Moreover, the extracts were characterized for the constituents and the antioxidant properties to correlate with the MGAT2 inhibition.

\section{RESULTS}

2.1. Feeding of 2-MAG Results in TAG Accumulation in the HIEC- 6 Cell Line. The HIEC- 6 cells were fed with exogenous 2-MAG, diacylglycerol (DAG), and TAG, each at four different increasing concentrations. The concentration of accumulated TAG in the cells was estimated, and the results are shown in Figure 1. The media control and vehicle control showed a basal level of TAG present in the cells. However, the 


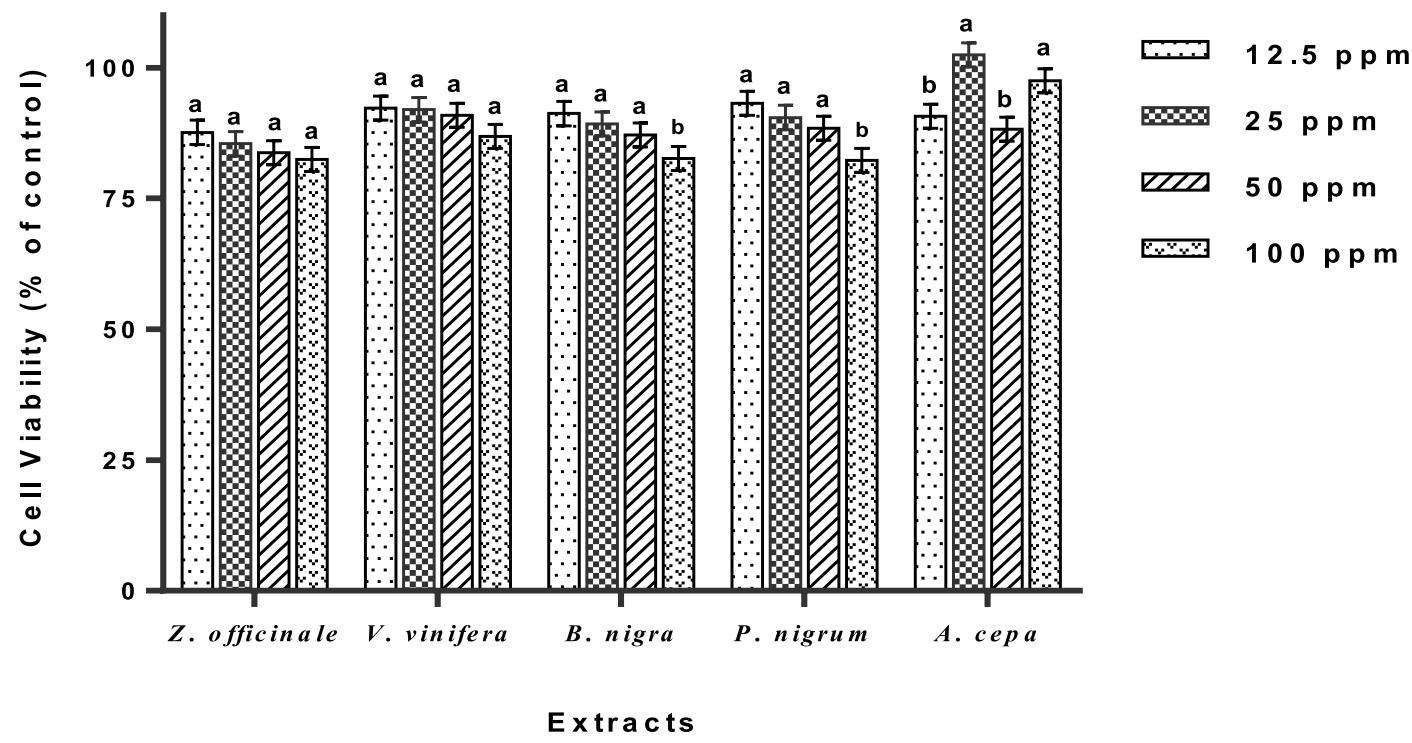

Figure 3. Effect of selected aqueous plant extracts on cell viability in HIEC-6 cells. The concentrations were 12.5, 25, 50, and 100 ppm for each extract. Values are means $\pm \mathrm{SD}(n=3)$ of data from two separate experiments with three replicates. Mean values with the same superscript letters are not significantly different, whereas those with different superscript letters differ significantly $(P<0.05)$ as analysed by Duncan's multiple range tests.

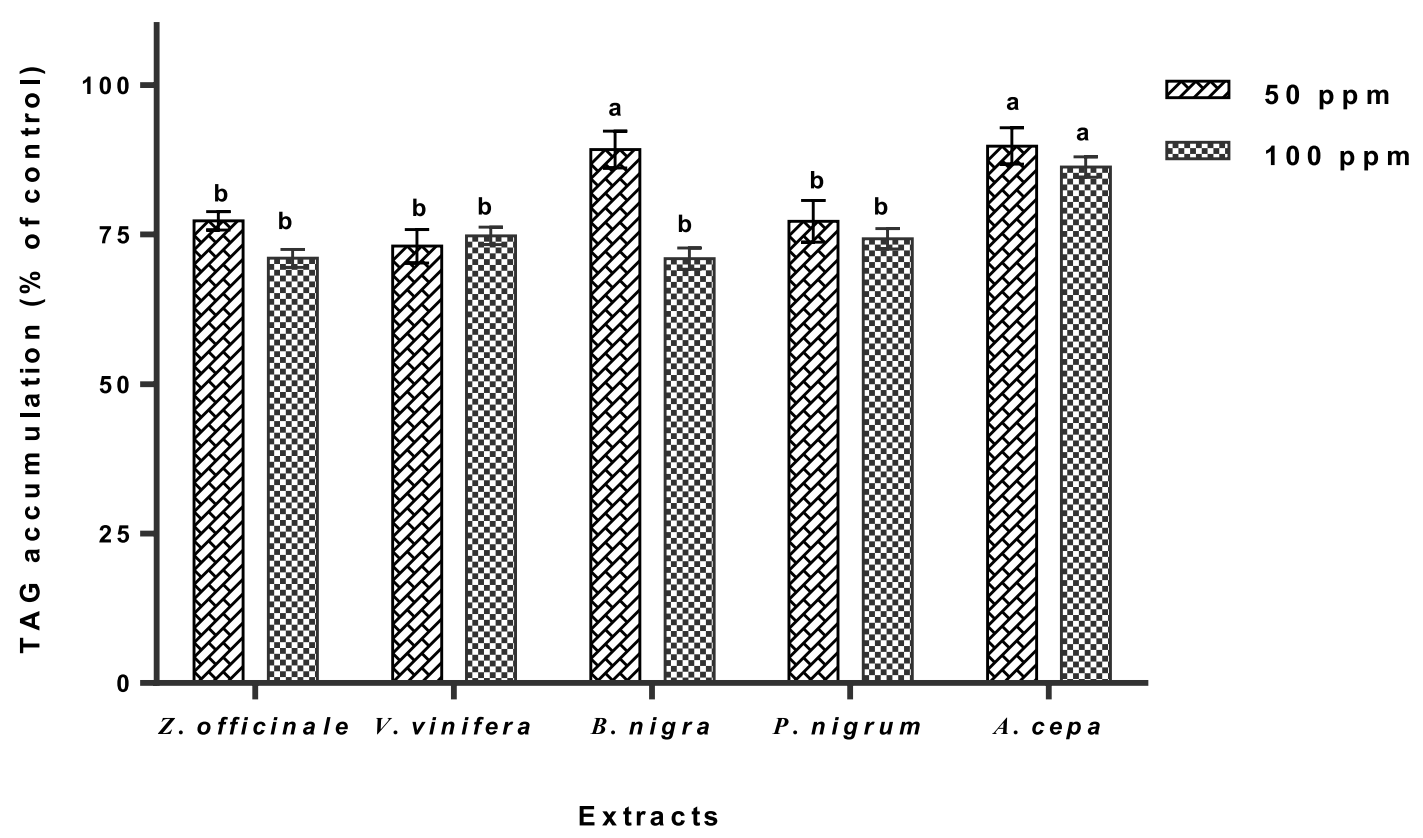

Figure 4. Effect of selected aqueous plant extracts on TAG accumulation in HIEC-6 cells. $200 \mu \mathrm{M}$ of 2-MAG was used to induce TAG accumulation in HIEC-6 cells. For each extract, the concentrations used were 50 and $100 \mathrm{ppm}$. TAG quantification was performed as described in the Materials and Methods section. Results are summarized from three experiments conducted in duplicate. Mean values with the same superscript letters are not significantly different, whereas those with different superscript letters differ significantly $(P<0.05)$ as analyzed by Duncan's multiple range tests.

cells fed with exogenous 2-MAG showed TAG accumulation in HIEC-6 cells in a dose-dependent manner. The 2-MAGinduced TAG formation was also visualized by BODIPY staining of HIEC-6 cells. The BODIPY stains neutral lipid droplets that consist mostly of TAG and show them as distinctive green fluorescent spots (Figure 2). As can be seen, the TAG formation was at the basal levels in the cells incubated with media and with the vehicle alone. The presence of 2 -MAG at 100,200 , and $400 \mu \mathrm{M}$ concentration in media facilitated TAG formation in HIEC-cells in a concentrationdependent manner as observed from the increase in fluorescence vis-à-vis the accumulation of TAG. The BODIPY staining confirms the accumulation of TAG, which was previously measured quantitatively. Based on the results, 200 $\mu \mathrm{M}$ 2-MAG concentration was used for the further experiments.

2.2. Nature and Yield of Plant Extracts. The nature and yield of five aqueous extracts from different plants are presented in Table S1. Except for the Allium cepa extract that was in the resin form, all the other extracts were in powder form. The extract yield varied from 2.42 to $5.62 \%$. 


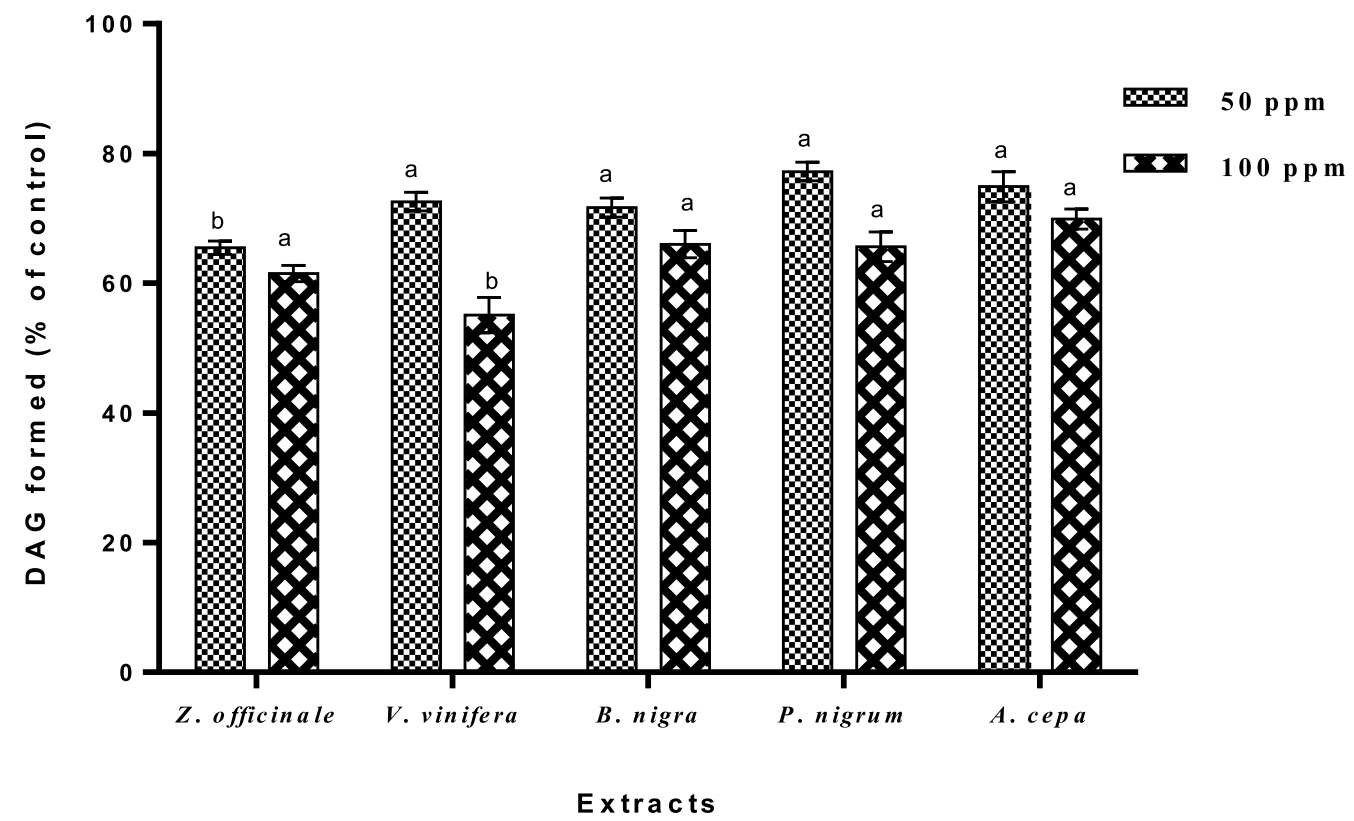

Figure 5. Effect of different extracts on MGAT2 activity in the intestinal homogenate. The MGAT2 activity assay was performed using the mouse intestinal homogenate as the enzyme source described in the Materials and Methods section. $\left[{ }^{14} \mathrm{C}\right]$ Oleoyl CoA was used as an acyl donor, and radiolabelled DAG formed was estimated by liquid scintillation counting. For each extract, 50 and $100 \mathrm{ppm}$ concentration were added in the assay to see its effect on the enzyme activity in form of radiolabelled DAG formation. Results are summarized from three experiments conducted in duplicate. Mean values with the same superscript letters are not significantly different, whereas those with different superscript letters differ significantly $(P<0.05)$ as analyzed by Duncan's multiple range tests.

\subsection{Plant Extracts and Cell Viability Assay in HIEC-6} Cell Line. To validate that the described cell-based assay can be used to screen plant extract, five plants were shortlisted. The aqueous extracts were prepared from these plants and were subjected to MTT assay using the HIEC-6 cell line to ascertain the safety/toxicity. The cell toxicity assay was performed for all the extracts at different concentrations, such as 12.5, 25, 50, and $100 \mathrm{ppm}$. The maximum cell death (18\%) was observed with extracts of Zingiber officinale (100 ppm), Piper nigrum (100 ppm), and Brassica nigra (100 ppm), followed by Vitis vinifera $(100 \mathrm{ppm})$ and A. cepa (50 ppm) extracts (Figure 3$)$. At the lower concentrations, no significant cytotoxicity was observed in all the extracts. The cell death of less than $20 \%$ was considered non-toxic and safe, and hence, it was considered for further studies. ${ }^{14}$

2.4. Effect of Plant Extracts on 2-MAG-Induced TAG Accumulation in HIEC-6 Cell Line. The extracts were evaluated for their effect on 2-MAG-induced TAG accumulation in the HIEC- 6 cells. The assay was tested with 50 and $100 \mathrm{ppm}$ of extract concentrations as the lower concentrations did not show a considerable difference in TAG accumulation. Out of the tested extracts, the $V$. vinifera extract at $50 \mathrm{ppm}$ and $Z$. officinale extracts at $100 \mathrm{ppm}$ showed the lowest TAG accumulations of 73.07 and $70.75 \%$, respectively (Figure 4). The A. cepa extract showed the maximum TAG accumulation at both concentrations ( 89.81 and $86.29 \%$ ). Overall, all the extracts showed approximately $25 \%$ inhibition of TAG accumulation at the studied concentrations.

2.5. Effect of Plant Extracts on MGAT2 Activity in the Intestinal Microsome. In the HIEC-6 based assay, the plant extracts used in this study showed inhibition of 2-MAGinduced TAG accumulation. Out of the three MGAT isoforms, MGAT1 is not expressed in the intestine, whereas MGAT3 is expressed in the human but not in mouse intestine. ${ }^{15,16}$ Hence, any MGAT activity seen in the mouse intestinal microsomes can be attributed only to MGAT2. Effect of these extracts on the in vitro MGAT2 activity in mouse intestinal microsomes are shown in Figure 5. The conversion of 2-MAG to DAG by the MGAT2 enzyme was normalized and considered as cent percent. All five extracts were evaluated at two different concentrations (50 and $100 \mathrm{ppm}$ ). Both Z. officinale extract and $V$. vinifera extract at $100 \mathrm{ppm}$ showed approximately $60 \% \mathrm{DAG}$ formation than vehicle control indicating $40 \%$ inhibition in MGAT2 activity. The A. cepa, $P$. nigrum, and $B$. nigra extracts at $100 \mathrm{ppm}$ concentration showed approximately 30\% inhibition in MGAT2 activity. At lower concentrations (50 $\mathrm{ppm}$ ), all the extracts showed less inhibition when compared to higher concentrations. The Z. officianale extract showed maximum MGAT2 inhibitory activity. The MGAT2 inhibition activities of these extracts corroborated with the cell-based assay results, wherein the $V$. vinifera and $Z$. officianale extracts showed the least TAG accumulations in the HIEC- 6 cells. Hence, it can be inferred that the 2-MAG-induced TAG accumulation in the HIEC-6 cell is via MGAT2, and inhibition of the TAG accumulation can be an indicator for MGAT2 inhibitory activity in the HIEC-6 cells. Therefore, the HIEC-6 based assay can be used to screen for potential MGAT2 inhibitors.

2.6. Antioxidant Activity and HPLC Profiling of Phytochemical Bioactive Compounds Present in the Extracts. The enzymatic inhibition shown by the plant extracts can be attributed to their antioxidant activities and the presence of bioactive compounds. The antioxidant assays for different extracts were performed by DPPH, ABTS, and FRAP methods and are presented in Table 1 . These are the best methods for analyzing antioxidant and free radical scavenging activity in the studied samples. ${ }^{17}$ The DPPH assay revealed a better IC50 value at a lesser concentration of $0.23 \mu \mathrm{g} / \mathrm{mL}$ for $V$. vinifera extract, followed by Z. officinale and $P$. nigrum extracts. The $B$. nigra and $A$. cepa extracts showed the 
Table 1. IC50 of Antioxidant Assays for Different Extracts From Selected Plant Sources ${ }^{a}$

$\begin{array}{cccc}\text { extract name } & \begin{array}{c}\mathrm{DPPH} \\ (\mathrm{IC} 50-\mu \mathrm{g} / \mathrm{mL})\end{array} & \begin{array}{c}\text { ABTS } \\ (\mathrm{IC} 50-\mu \mathrm{g} / \mathrm{mL})\end{array} & \begin{array}{c}\text { FRAP } \\ (\mathrm{IC} 50-\mu \mathrm{g} / \mathrm{mL})\end{array} \\ \begin{array}{c}\text { ginger }(Z . \\ \text { officinale })\end{array} & 0.68 \pm 0.11^{\mathrm{a}} & 0.089 \pm 0.017^{\mathrm{b}} & 1.58 \pm 0.29^{\mathrm{b}} \\ \begin{array}{c}\text { grape }(V . \\ \text { vinifera })\end{array} & 0.23 \pm 0.14^{\mathrm{a}} & 0.031 \pm 0.004^{\mathrm{a}} & 0.87 \pm 0.12^{\mathrm{a}} \\ \begin{array}{c}\text { mustard }(B . \\ \text { nigra })\end{array} & 1.98 \pm 0.27^{\mathrm{b}} & 0.172 \pm 0.028^{\mathrm{c}} & 3.56 \pm 0.43^{\mathrm{c}} \\ \begin{array}{c}\text { pepper }(P . \\ \text { nigrum })\end{array} & 0.97 \pm 0.18^{\mathrm{a}} & 0.083 \pm 0.025^{\mathrm{b}} & 2.78 \pm 0.35^{\mathrm{b}} \\ \text { onion }(A . \text { cepa }) & 1.87 \pm 0.23^{\mathrm{b}} & 0.231 \pm 0.048^{\mathrm{c}} & 5.51 \pm 0.86^{\mathrm{d}}\end{array}$

${ }^{a}$ Mean values with the same superscript letters are not significantly different, whereas those with different superscript letters differ significantly $(P<0.05)$ as analyzed by Duncan's multiple range tests. Values are means $\pm \mathrm{SD}(n=3)$ of data from two separate experiments with three replicates.

IC50 value for DPPH at $\sim 2 \mu \mathrm{g} / \mathrm{mL}$. A similar trend could be observed in ABTS and FRAP assays. The $V$. vinifera extract showed better results across all assays, and the $A$. cepa was the least active among all the studied extracts. It is also noted that the $V$. vinifera extract possesses better antioxidant activity at lower concentrations.

The HPLC analysis was performed to identify the major constituents of the studied extracts. As can be seen from the chromatograms given in Figure S1, the major compounds identified were curcumin and epicatechin in the $Z$. officinale (ginger) extract, epicatechin, and cinnamic acid in the $V$. vinifera (black grape) extract, myristic acid, and epicatechin in the $B$. nigra (mustard) extract, piperine in the $P$. nigrum (pepper) extract, and quercetin in the A. cepa (red onion) extract. These identified bioactives have been shown to have anti-obesity activities.

\section{DISCUSSION}

Obesity is a major metabolic syndrome affecting one-third of the U.S population and a significant risk factor for many disorders such as diabetes, non-alcoholic steatohepatitis, cardiovascular diseases, and a few types of cancers. ${ }^{18}$ Because of safety and efficacy concerns, only $3 \%$ of the obese population is treated with orlistat, phentermine, lorcaserin, and topiramate. ${ }^{19}$ Orlistat is a major drug that blocks fat absorption by approximately $30 \% .{ }^{20}$ However, the use of orlistat is limited because of its low GI tolerability. Hence, there is a need to find alternative remedies for similar drug targets with improved GI tolerability.

The ingested dietary TAG gets digested to MAG, DAG, and free fatty acids by pancreatic lipase. These get absorbed in the intestine and re-esterified back to TAG by two significant enzymes, namely, MGAT2 and DGAT, through the MAG pathway in the enterocyte. ${ }^{9}$ These enzymes play a crucial role in TAG biosynthesis. Upregulation of these enzymes leads to triglyceride accumulation in adipose tissues leading to metabolic disorders such as obesity and diabetes. ${ }^{21}$

The obstruction of dietary TAG absorption and its resynthesis in the enterocyte has been explored as a potent pathway in targeting obesity. The MGAT and DGAT inhibitors have been shown to control and treat these metabolic diseases and currently few DGAT inhibitors are in clinical trials. ${ }^{22}$ The mgat 2 gene manipulation and pharmacological treatment with MGAT2 inhibitors in mice delay fat absorption and suppress plasma TAG. This leads to decreased food intake and weight loss, which supports targeting the MAG pathway as a potent and viable therapeutic target for intestinal TAG resynthesis. ${ }^{23,24}$ By inhibiting MGAT2 in the intestine, vital changes in TAG and cholesterol absorption lead to the release of gut incretin and changes in systemic energy homeostasis. ${ }^{21}$ Few such compounds/formulations are in various stages of preclinical and clinical trials. These remedies are now gaining significant importance in treating metabolic diseases. ${ }^{25}$ Most of the MGAT2 inhibitors have been patented by pharmaceutical companies, such as bicyclic pyrimidine derivatives by Sumitomo Dainippon Pharma in Japan, isoindoline-2-carboxamide and 1,2,3,4-tetrahydroisoquinoline by Taisho Pharmaceutical Co., Tokyo, morpholinyl derivatives by Eli Lilly and Co., USA, tetrahydropyridopyrimidinone derivatives by Ajinomoto Co., Japan, sulfonamide derivatives by Takeda Pharma Co., Osaka, Japan, pyridinone derivatives by Bristol Myers Squibb Co., USA, and dihydropyridinone analogues by Merck Sharp and Dohme Corp., Canada. The known MGAT2 inhibitors are pure chemical compounds or their derivatives and are associated with various side effects. ${ }^{25}$

A simple, robust, throughput assay method is warranted to accelerate the discovery of safe drugs/compounds with fewer side effects. For profiling such MGAT2 inhibitors, a cell-based assay of MGAT2-driven DAG with murine secretin tumor cells-1 was developed by Bristol Myers Squibb Co., USA. However, the utilization of isotope labeling and high-resolution LC/MS limited scope. ${ }^{21}$ Park et al. optimized the enzyme activity assay for screening MGAT2 inhibitors with MGAT2 expression in hMGAT2-Hep3B cells. The sophisticated expression studies limited the assay utility. ${ }^{26}$ In another study, a chemical probe method with enzyme inhibitory kinetics by binding of MGAT2 inhibitors to MGAT2 was developed but limited the scope, as a cell-based assay is preferred over the ex situ enzyme binding method. ${ }^{27}$ Hence, the present assay based on HIEC- 6 cells with 2-MAG helps overcome the shortcomings and can be a simple, substratedriven robust technique to screen MGAT2 inhibitors.

In our study, the 2-MAG was fed to HIEC-6 cells, and we had evaluated the TAG accumulation to standardize the MGAT2 inhibition assay. The exogenous 2-MAG at various concentrations were provided to cells to assess triglycerides in the cells. With the increase in the concentration of 2-MAG, there was an increase in TAG formation in the cells. To analyze the effect of other MAG pathway intermediates on TAG accumulation, cells were fed with exogenous DAG and TAG at different concentrations. It was observed that neither DAG nor TAG had any effect on TAG accumulation in the cells. This demonstrates that only 2-MAG was able to enter the cells. The MGAT and DGAT utilized the endogenous acylCoAs for sequential esterification, resulting in TAG formation by the MAG pathway. The BODIPY was used to stain the neutral lipids and showed distinctive green fluorescent spots. The presence of $2-\mathrm{MAG}$ at 100,200 , and $400 \mu \mathrm{M}$ concentration in media facilitated TAG formation in HIECcells in a concentration-dependent manner as observed from the increase in fluorescence vis-à-vis the accumulation of TAG. The MGAT2 inhibition prevents the TAG accumulation by minimizing the conversion of MAG to DAG and finally to TAG. ${ }^{9}$ Hence, this HIEC- 6 cells-based assay can be used to screen for inhibitors that prevent TAG formation in the presence of 2-MAG via MGAT2 inhibition. 
There are no known proven MGAT2 inhibitors in the market. Besides, most pharma companies patented such inhibitors and are at different clinical/preclinical trials. ${ }^{25} \mathrm{We}$ could not obtain any known MGAT2 inhibitor to validate the present assay method. Because of the scope of safe and potent anti-obese leads from plant sources, we have chosen the natural extracts with potent bioactive substances/compounds to validate the present assay. Incidentally, the cell-based assay developed with HIEC- 6 cells could be validated with plant extracts with proven anti-obesity properties.

After standardization of the MGAT inhibition assay, five plant extracts on 2-MAG-induced TAG accumulation in HIEC-6 were studied. Unuofin et al. reported the anti-obesity activity of Vernoniam espilifolia extracts in vitro using HeLa cells. ${ }^{28}$ Shen et al. investigated the effect of chia oil on TAG accumulation in the HepG2 cell line model, ${ }^{29}$ wherein the Mexican chia oil lowered TAG accumulation by $25.8 \%$ in the cells. In the current study, the $Z$. officinale extract showed the maximum inhibition (29.25\%) of TAG accumulation. Our results showed that the HIEC- 6 cell-based assay could be used to screen the plant extracts that can inhibit 2-MAG-induced TAG accumulation.

All the extracts were used to study the effect on 2-MAGinduced TAG accumulation in the HIEC-6 cells, and the $V$. vinifera extract and $Z$. officinale extracts showed the least TAG accumulation. Further, the plant extracts were assayed for MGAT2 activity with intestinal microsomes. The absorption of dietary fat in the enterocytes involves the re-esterification of digested TAG by MGAT2. The $Z$. officinale and $V$. vinifera extracts revealed better DAG formation control and showed promising inhibition of MGAT2 activity.

The antioxidant activity of extracts was evaluated by three different methods and was compared. All the aqueous extracts showed good antioxidant activities. The HPLC profiling of the various plant extracts revealed that they were rich in few polyphenols with good antioxidant activity. The major polyphenols present in these plant extracts were curcumin, epicatechin, cinnamic acid, myricetin, rosmarinic acid, piperine, and quercetin. The polyphenols were identified by HPLC and matched with those reported in earlier literature. $^{30-32}$

The MGAT2 inhibition activities of the extracts studied using mouse intestinal microsomes align with the cell-based assay results. Therefore, the HIEC- 6 based assay can be used to screen for potential MGAT2 inhibitors. It has also given an insight into potent bioactive MGAT2 inhibitors present in natural sources. This assay avoids radio-labeling, gene expression, and sophisticated equipment; instead, it uses simple cells, substrate, and methodology. Hence, this can be used as a simple and robust assay for screening MGAT2 inhibitors. It will be interesting to screen synthetic or chemical inhibitors using the described assay. Besides, this assay can be automated, and high throughput screening can be performed with the help of robotics to screen compound libraries.

\section{CONCLUSIONS}

To accelerate the drug discovery process for metabolic disorders such as obesity, cardiovascular disease, non-alcoholic fatty liver disease, there is a need for simple, robust assays. In our present study, we developed a simple assay to screen lead molecules for MGAT2 inhibition through the MAG pathway. Even though earlier attempts were made to evaluate MGAT2 activity by overexpression, cloning, isotope-labeled substrate, we standardized a simple cell-based assay using the HIEC-6 cell line MGAT-2 inhibition. We found feeding of 2-MAG to cells led to the accumulation of triglycerides mimicking the adipogenicity in obese condition. The same was confirmed by confocal imaging of BODIPY-stained TAG accumulated cells. The assay was validated by in vitro assay with intestinal microsomes as a source of enzyme. Further, we evaluated the developed assay's efficacy by screening five different plantbased aqueous extracts for MGAT2 inhibition. This is the first report for the development and evaluation of cell-based assay to screen MGAT-2 inhibitors using HIEC-6 cell line.

\section{MATERIALS AND METHODS}

5.1. Chemicals. The HIEC-6 (ATCC CRL-3266) cell line was obtained from American Type Culture Collection, OptiMEM reduced serum medium, HEPES [4-(2-hydroxyethyl)-1-piperazine ethane sulfonic acid], GlutaMAX, and recombinant mouse epidermal growth factor were procured from Gibco Thermo Scientific, Bangalore, India. The antibiotic antimycotic solution, fetal bovine serum, $0.25 \%$ trypsinEDTA, phosphate buffer saline (pH-7.4), 3-(4,5-dimethylthiazol-2-yl)-2,5-diphenyl-tetrazolium bromide (MTT), 1× RIPA buffer were obtained from Himedia, Bangalore, India. Dimethyl sulfoxide, 1, 2-Diolein, and Triolein were purchased from Sigma-Aldrich, Bangalore, India. $\left[{ }^{14} \mathrm{C}\right]$ Oleoyl CoA was purchased from American Radiolabelled Chemicals, Inc, (St. Louis, MO, USA). Unlabeled 2-oleoyl glycerol was procured from Cayman Chemicals Co., USA. A commercial triglyceride estimation kit was obtained from Agappe diagnostics, Bangalore, India. BODIPY 493/503 stain from Invitrogen BioServices India Private Limited (Thermo Fisher, Bangalore, India). 2,5-Diphenyloxazolescintillation grade and 1,4-bis(5phenyl oxazole-2yl)-benzene scintillation grade and toluene from Sisco Research Laboratories Private Limited, Mumbai India.

5.2. Cell Culture. Preparation of Complete Growth Media: The base medium for the HIEC-6 cell line is OptiMEM 1 reduced serum medium. To prepare the complete growth medium, $20 \mathrm{mM}$ HEPES, $10 \mathrm{mM}$ GlutaMAX, $10 \mathrm{ng} / \mathrm{mL}$ epidermal growth factor, fetal bovine serum to a final concentration of $4 \%, 50 \mu \mathrm{g} / \mathrm{mL}$ of antibiotic antimycotic solution were added. HIEC-6 cells were maintained at $37^{\circ} \mathrm{C}$, supplied with $5 \% \mathrm{CO} 2$ in the humidified chamber on type I collagen-coated culture flasks in complete OptiMEM medium. The culture medium was changed every alternate day.

5.3. 2-Monoacylglycerol Feeding and Quantification of TAG Accumulation in HIEC-6. The cell density of $5 \times 10^{3}$ cells/well were seeded into a 96-well plate with complete optiMEM media. Cells were cultured until they reached the confluence of $70-80 \%$ at $37{ }^{\circ} \mathrm{C}$. The complete media were replaced with serum-free media $12 \mathrm{~h}$ before 2-MAG treatment. At $12 \mathrm{~h}, 2-\mathrm{MAG}$ was added in 4 different concentrations (50, $100,200$, and $400 \mu \mathrm{M})$, incubated for $1 \mathrm{~h}$, the media was removed and the cells were washed with PBS. To that, $100 \mu \mathrm{L}$ of cell lysis buffer ( $1 \times$ RIPA) was added to lyse the cells. Total triacyl glyceride was estimated in the lysate using a triglyceride assay kit (Agappe diagnostics ltd, Bangalore, India). The absorbance was recorded at $546 \mathrm{~nm}$. The same was carried out with exogenous DAG (1,2-diolein) and TAG (triolein) in place of 2-MAG treatment.

5.4. Determination of 2-MAG-Induced TAG Accumulation in HIEC-6 Cells. The HIEC- 6 cells were seeded in a pre-autoclaved coverslip which contained 6 well plates. To 
induce TAG accumulation in cells, complete media was replaced with serum-free media after obtaining $70 \%$ confluence performed $12 \mathrm{~h}$ before 2-monooleoylglycerol (MAG) treatment. 2-MAG was dissolved in ethanol (0.5\%) and fed to cells at different concentrations to a total volume of $2 \mathrm{~mL}$, and the plates were incubated for $1 \mathrm{~h}$. After $12 \mathrm{~h}$, the cells were taken out and rinsed with $1 \times \mathrm{PBS}$; then, $1 \mathrm{~mL}$ of $4 \%$ formalin solution was added to the plate and incubated for $30 \mathrm{~min}$ at 37 ${ }^{\circ} \mathrm{C}$ in a $\mathrm{CO}_{2}$ incubator to fix the cells. Later, the plates were taken out and washed with $1 \times$ PBS twice to remove the residual fixing solution, and finally, the BODIPY staining was performed. The extract treatment was given $2 \mathrm{~h}$ before $2-\mathrm{MAG}$ treatment and followed the same procedure as discussed above.

The BODIPY stock $(1 \mathrm{mg} / \mathrm{mL})$ was prepared, and the working concentration of $1 \mu \mathrm{g} / \mathrm{mL}$ was used for further staining. For each cultured well, $800 \mu \mathrm{L}$ of stain was added, and the plate was incubated in the dark at ambient room temperature for $30 \mathrm{~min}$. After incubation, the plates were rinsed thrice $1 \times$ PBS to remove excess stain. After that, the coverslip was taken out from the culture plate and mounted on a glass slide. The stained cells were imaged at an excitation wavelength of $493 \mathrm{~nm}$ and an emission wavelength of $503 \mathrm{~nm}$ in green fluorescent wavelength with $20 \times$ magnification. $^{33,34}$

5.5. Plant Materials. Five (5) locally available plant materials such as Z. officinale Rosc. (ginger), V. vinifera Linn. (grape seed), B. nigra Koch. (mustard), P. nigrum Linn. (pepper), and A. cepa Linn. (red onion) were selected, and the parts of the plants used are listed in Table S1. The raw materials were procured from the local market of Mysuru, Karnataka, India. The collected sources were cleaned, washed with distilled water, and dried in a hot air oven (Biobee Tech, Bangalore) for $48 \mathrm{~h}$ at $50{ }^{\circ} \mathrm{C}$ temperature. The dried samples were pulverized to powder by using a mixer grinder for $20 \mathrm{~min}$ at high speed. The powdered samples were stored in airtight bags at $4{ }^{\circ} \mathrm{C}$ until further use.

5.6. Preparation of Plant Extracts. The powdered samples were defatted using Soxhlet extraction with hexane at $65{ }^{\circ} \mathrm{C}$ to ensure no exogenous lipids' interference in further experiments. The defatted samples were dried in an oven set at $50{ }^{\circ} \mathrm{C}$ and further used to prepare the water extract in a $1: 10$ $(\mathrm{w} / \mathrm{v})$ ratio. The samples were kept in a shaker for $24 \mathrm{~h}$ at room temperature. The extracts were filtered through muslin cloth followed by Whatman no.1 filter paper, and finally, the filtrate was centrifuged at $5000 \mathrm{rpm}$ for $10 \mathrm{~min}$ (Thermo scientific ST 8R). The obtained clear filtrates were freeze-dried at $-40{ }^{\circ} \mathrm{C}$ (FreeZone Plus, LABCONCO, USA) and stored at $-20{ }^{\circ} \mathrm{C}$ till further use.

For the experiments, $50 \mathrm{mg}$ extracts were dissolved in $1 \mathrm{~mL}$ of distilled water to get the stock concentration of $50000 \mathrm{ppm}$. From this stock solution, the working concentrations of 12.5, 25, 50, and 100 ppm were prepared.

5.7. Effect of Different Extracts on HIEC-6 Cell Viability. The cytotoxicity of the plant extracts was evaluated using the MTT assay. The HIEC-6 cells were seeded $\left(5 \times 10^{4}\right.$ cells/well) in a 96 well plate; after reaching 70-80\% confluency, cells were fed with different concentrations of extracts $(12.5,25,50$, and $100 \mathrm{ppm})$ to a final volume of 100 $\mu \mathrm{L}$ and incubated for $24 \mathrm{~h}$. After $24 \mathrm{~h}$ of incubation, the cells were rinsed with $1 \times \mathrm{PBS}$; then, $100 \mu \mathrm{L}$ of MTT solution was added and incubated for $4 \mathrm{~h}$ at $37^{\circ} \mathrm{C}$ in a $\mathrm{CO}_{2}$ incubator (New Brunswick, Galaxy 170R, Eppendorf Company). The washed cells were then treated with $50 \mu \mathrm{L}$ of dimethyl sulfoxide (DMSO) and mixed to solubilize the formazan crystals formed by living cells. ${ }^{35}$ Absorbance was measured at $570 \mathrm{~nm}$ in a microplate reader (TECAN spark cyto, Switzerland). The cell viability (\%) was calculated in percentage according to the following equation

$$
\text { cell viability }(\%)=\frac{A 570(\text { sample })}{A 570(\text { control })} \times 100
$$

5.8. Screening of Plant Extracts on Inhibition of TAG Accumulation in the HIEC- 6 Cells. Cells were cultured for 4 days at $37^{\circ} \mathrm{C}$ after seeding with $5 \times 10^{3}$ cells/well in a 96-well plate with complete optiMEM media.

Post confluency, the complete media were replaced with serum-free media $12 \mathrm{~h}$ before 2-MAG treatment. Extracts were added in two different concentrations (50 and $100 \mathrm{ppm}$ ) $2 \mathrm{~h}$ before 2-MAG treatment. At $12 \mathrm{~h}, 2-\mathrm{MAG}$ treatment (200 $\mu \mathrm{M})$ was given and incubated for a further $1 \mathrm{~h}$. Then, the spent media were removed and the cells were rinsed with PBS, three to four times to remove any exogenous lipid. Then, $100 \mu \mathrm{L}$ of cell lysis buffer (RIPA) was added to each well to lyse the cells. The triglyceride in the lysate was measured using a triglyceride assay kit (Agappe diagnostics ltd, Bangalore, India).

5.9. Intestinal Microsome Preparation. Microsome preparation was performed following the published work with slight modification. ${ }^{36}$ The proximal part of the small intestine was collected from C57BL/6 mice from the institute animal house facility. The intestinal lumen was perfused with saline to make the intestine free from fecal content. The intestinal scrapings were homogenized with $10 \mathrm{~mL}$ of $0.1 \mathrm{M}$ sodium phosphate buffer saline $(\mathrm{pH} 7.4)$ containing $0.25 \mathrm{mM}$ phenylmethylsulphonyl fluoride and $1.0 \mathrm{mM}$ dithiothreitol. This suspension was homogenized for $3 \mathrm{~min}$ at $30 \mathrm{~s}$ intervals using a homogenizer with $3000 \mathrm{rpm}$ speed. The homogenate was centrifuged at $5000 \mathrm{rpm}$ at $4{ }^{\circ} \mathrm{C}$ for $15 \mathrm{~min}$ (Eppendorf 5415R), and the supernatant was collected. The supernatant was again centrifuged to $12,000 \mathrm{rpm}$ for $30 \mathrm{~min}$ at $4{ }^{\circ} \mathrm{C}$. The supernatant was collected and subjected to ultra-centrifugation at $30,000 \mathrm{rpm}$ at $4{ }^{\circ} \mathrm{C}$ for $1 \mathrm{~h}$ (Optima-100, Beckman). The microsomal pellet was transferred to a homogenizing tube and resuspended in $4 \mathrm{~mL}$ of $0.1 \mathrm{M}$ sodium phosphate buffer saline (pH-7.4) containing $1.0 \mathrm{mM}$ dithiothreitol and $0.25 \mathrm{M}$ sucrose. This suspension was homogenized again gently with the homogenizer, which was set to $3000 \mathrm{rpm}$. A $0.1 \mathrm{~mL}$ aliquot was immediately frozen and stored at $-80{ }^{\circ} \mathrm{C}$. Microsomal protein concentration was determined in triplicate by a standard method using BSA standard. ${ }^{37}$

5.10. MGAT2 Assay Using Intestinal Microsome. MGAT2 activity assays were performed with total tissue microsomes as described. ${ }^{38}$ The incorporation of $\left[{ }^{14} \mathrm{C}\right]$ oleoylCoA into sn-2-oleoyl glycerol was measured to assay the MGAT2 activity. The reaction mixture consists of $100 \mathrm{mM}$ Tris- $\mathrm{HCl}$ (pH 7.0), $200 \mu \mathrm{M}$ 2-oleoyl glycerol (MAG), $20 \mathrm{mM}$ magnesium chloride $\left(\mathrm{MgCl}_{2}\right)$, and $25 \mu \mathrm{M}$ cold 18:1 acyl-CoA dissolved in $5 \mathrm{mM}$ CHAPS solution, $80 \mu \mathrm{g}$ of microsomal protein fraction, and $363.63 \mathrm{pmol}$ or $0.02 \mu \mathrm{Ci} / \mathrm{mol}$ of $\left[{ }^{14} \mathrm{C}\right]$ Oleoyl CoA. The reaction was initiated by adding microsomal protein and terminated by chloroform: methanol $(2: 1 \mathrm{v} / \mathrm{v})$ after pre-determined incubation periods and separated by TLC with hexane: ethyl ether: acetic acid (80:20:1) as the mobile phase. The bands corresponding to DAG were scrapped after iodine staining. Scraped silica bands were transferred into scintillation vials for counting of radioactivity. The scintillation vials were subjected to Liquid Scintillation Analyzer-Quanta 
Smart (PerkinElmer, Boston, MA, USA) and the readings were recorded as counts per min. To study plant extract's effect on MGAT2 activity, the extracts were added in the MGAT2 assay at 50 and $100 \mathrm{ppm}$ concentration. The assay was carried out as mentioned above, and results were recorded in triplicates.

5.11. Antioxidant Activity of Selected Plant Extracts. The antioxidant potential was evaluated by in vitro free radical scavenging activity by 2, 2-diphenyl-1-picrylhydrazyl (DPPH) method, ${ }^{39}$ 2,2' -azino-bis-3-ethylbenzothiazoline-6-sulphonic acid (ABTS) method, ${ }^{40}$ and ferric reducing antioxidant power assay (FRAP) method. ${ }^{41}$

5.12. Identification of Major Components in the Extracts by HPLC Analysis. To characterize the aqueous extracts, the samples were defatted, and polyphenols were extracted and estimated by HPLC. The polyphenolic and flavonoid profile was analyzed by HPLC connected with the C18 column (Shimadzu, SPD-M30A, Japan). The polyphenols and flavonoids are detected at 280 and $320 \mathrm{~nm}$, respectively. The polyphenols and flavonoids present in the samples were quantified by comparing them with the standards.

5.13. Statistical Analysis. All the data were obtained in triplicate and subjected to statistical analysis. Significant differences between groups were evaluated using one-way analysis of variance (ANOVA) followed by Duncan's post hoc comparison test. All the results are expressed as mean \pm standard deviation (SD). For all the results, $p<0.05$ was considered statistically significant.

\section{ASSOCIATED CONTENT}

\section{SI Supporting Information}

The Supporting Information is available free of charge at https://pubs.acs.org/doi/10.1021/acsomega.0c05950.

Characteristics of extracts from selected plant sources and major constituent identification (PDF)

\section{AUTHOR INFORMATION}

\section{Corresponding Author}

Ajay W. Tumaney - Academy of Scientific and Innovative Research (AcSIR), Ghaziabad 201002, India; Department of Lipid Science, Council of Scientific and Industrial Research-Central Food Technological Research Institute, Mysuru 570 020, India; (1) orcid.org/0000-0003-37080123; Email: ajay@cftri.res.in

\section{Authors}

Yeshvanthi Singh - Academy of Scientific and Innovative Research (AcSIR), Ghaziabad 201002, India; Department of Lipid Science, Council of Scientific and Industrial Research-Central Food Technological Research Institute, Mysuru 570 020, India; 이이.org/0000-0002-56502603

Akshay Datey - Department of Microbiology and Cell Biology, Indian Institute of Science, Bangalore 560012, India

Dipshikha Chakravortty - Department of Microbiology and Cell Biology, Indian Institute of Science, Bangalore 560012, India

Complete contact information is available at:

https://pubs.acs.org/10.1021/acsomega.0c05950

\section{Author Contributions}

A.W.T. and D.C. conceptualized, designed the study, supervised, reviewed the results, and finalized the manuscript.
Y.S. established the protocols, executed the experiments, interpreted the results, and prepared the manuscript. A.D. standardized the radio-labeled assay and assisted in carrying out the same.

\section{Funding}

This work was supported through MLP0170 by the Council of Scientific and Industrial Research-Central Food Technological Research Institute, Mysuru, India.

Notes

The authors declare no competing financial interest.

\section{ACKNOWLEDGMENTS}

Y.S. gratefully acknowledges the Department of Science and Technology, Government of India. New Delhi, India, for the award of DST-INSPIRE fellowship (no. DST/INSPIRE Fellowship/2015/IF150228) to carry out this study. The authors would like to thank Dr. P Vijayaraj, Department of Lipid Science, CSIR-CFTRI, Mysore, India, for his critical comments on this manuscript. Finally, the authors thank Director, CSIR-CFTRI for the infrastructural facilities, support, and encouragement.

\section{ABBREVIATIONS}

MAG, monoacylglycerol; DAG, diacylglycerol; TAG, triacylglycerol; MGAT2, monoacylglycerol acyltransferase 2; DGAT, diacylglycerol acyltransferase; HEPES, 2-(hydroxyethyl)-1piperazine ethane sulfonic acid; MTT, 3-(4,5-dimethylthiazol-2-yl)-2,5-diphenyl-tetrazolium bromide; DMSO, dimethyl sulfoxide; HIEC-6, human intestinal epithelial cell line-6

\section{REFERENCES}

(1) Yadav, K.; Krishnan, A. Changing Patterns of Diet, Physical Activity and Obesity among Urban, Rural and Slum Populations in North India. Obes. Rev. 2008, 9, 400.

(2) Cao, J.; Hawkins, E.; Brozinick, J.; Liu, X.; Zhang, H.; Burn, P.; Shi, Y. A Predominant Role of Acyl-CoA: Monoacylglycerol Acyltransferase-2 in Dietary Fat Absorption Implicated by Tissue Distribution, Subcellular Localization, and Up-Regulation by High Fat Diet *. J. Biol. Chem. 2004, 279, 18878-18886.

(3) Yen, C.-L. E.; Farese, R. V. MGAT2 , a Monoacylglycerol Acyltransferase Expressed in the Small Intestine. J. Biol. Chem. 2003, 278, 18532-18537.

(4) Cheng, D.; Nelson, T. C.; Chen, J.; Walker, S. G.; WardwellSwanson, J.; Meegalla, R.; Taub, R.; Billheimer, J. T.; Ramaker, M.; Feder, J. N. Identification of Acyl Coenzyme A:Monoacylglycerol Acyltransferase 3, An Intestinal Specific Enzyme Implicated in Dietary Fat Absorption. J. Biol. Chem. 2003, 278, 13611-13614.

(5) Shi, Y.; Burn, P.; Care, B. H.; Lane, M. Lipid Metabolic Enzymes Emerging Drug Targets for the Treatment of Obesity. Nat. Rev. Drug Discovery 2004, 3, 695.

(6) Barlind, J. G.; Buckett, L. K.; Crosby, S. G.; Davidsson, Ö.; Emtenäs, H.; Ertan, A.; Jurva, U.; Lemurell, M.; Gutierrez, P. M.; Nilsson, K.; O'Mahony, G.; Petersson, A. U.; Redzic, A.; Wågberg, F.; Yuan, Z.-Q. Identification and Design of a Novel Series of MGAT2 Inhibitors. Bioorganic Med. Chem. Lett. 2013, 23, 2721.

(7) Kesavachandran, C. N.; Bihari, V.; Mathur, N. The Normal Range of Body Mass Index with High Body Fat Percentage among Male Residents of Lucknow City in North India. Indian J. Med. Res. 2012, 135, 72.

(8) Okuma, C.; Ohta, T.; Tadaki, H.; Hamada, H.; Oda, T.; Taniuchi, H.; Yamanaka, K.; Ishii, Y.; Ohe, Y.; Yata, S.; Nishiu, J.; Aratsu, Y.; Oshida, S.; Kume, S.; Kakutani, M. JTP-103237, a Novel Monoacylglycerol Acyltransferase Inhibitor, Modulates Fat Absorption and Prevents Diet-Induced Obesity. Eur. J. Pharmacol. 2015, 758, 72 . 
(9) Devasthale, P.; Cheng, D. Monoacylglycerol Acyltransferase 2 (MGAT2) Inhibitors for the Treatment of Metabolic Diseases and Nonalcoholic Steatohepatitis (NASH). J. Med. Chem. 2018, 61, 9879.

(10) Yen, C.-L. E.; Farese, R. V. MGAT2, a Monoacylglycerol Acyltransferase Expressed in the Small Intestine. J. Biol. Chem. 2003, $278,18532-18537$.

(11) Onorato, J. M.; Chu, C.-H.; Ma, Z.; Kopcho, L. M.; Chao, H. J.; Lawrence, R. M.; Cheng, D. Cell-Based Assay of MGAT2-Driven Diacylglycerol Synthesis for Profi Ling Inhibitors: Use of a Stable Isotope- Labeled Substrate and High-Resolution LC / MS. J Lipid Res. 2015, 56, 747-753.

(12) Montoudis, A.; Seidman, E.; Boudreau, F.; Beaulieu, J.-F.; Menard, D.; Elchebly, M.; Mailhot, G.; Sane, A.-T.; Lambert, M.; Delvin, E.; Levy, E. A Rapid and Sensitive Method for the Quantitation of Microgram Quantities of Protein Utilizing the Principle of Protein-Dye Binding. J. Lipid Res. 2008, 49, 961-972.

(13) Takenaka, T.; Harada, N.; Kuze, J.; Chiba, M.; Iwao, T.; Matsunaga, T. Application of a Human Intestinal Epithelial Cell Monolayer to the Prediction of Oral Drug Absorption in Humans as a Superior Alternative to the Caco-2 Cell Monolayer. J. Pharm. Sci. 2016, 105, 915-924.

(14) Lü, L.; Zhang, L.; Wai, M. S. M.; Yew, D. T. W.; Xu, J. Exocytosis of MTT Formazan Could Exacerbate Cell Injury. Toxicol. Vitr. 2012, 26, 636.

(15) Yue, Y. G.; Chen, Y. Q.; Zhang, Y.; Wang, H.; Qian, Y.-W.; Arnold, J. S.; Calley, J. N.; Li, S. D.; Perry, W. L.; Zhang, H. Y.; Konrad, R. J.; Cao, G. The Acyl CoenzymeA:Monoacylglycerol Acyltransferase 3 (MGAT3) Gene Is a Pseudogene in Mice but Encodes a Functional Enzyme in Rats. Lipids 2011, 46, 513.

(16) Nelson, D. W.; Gao, Y.; Yen, M.-I.; Yen, C.-L. E. IntestineSpecific Deletion of Acyl-CoA:Monoacylglycerol Acyltransferase (MGAT) 2 Protects Mice from Diet-Induced Obesity and Glucose Intolerance. J. Biol. Chem. 2014, 289, 17338.

(17) Dey, S.; Saxena, P. Review on different methods to assess the antioxidant activity of some common plants of indian traditional medicine. J. Drug Delivery Ther. 2011, 1, 36-39.

(18) Hruby, A.; Hu, F. B. The Epidemiology of Obesity: A Big Picture. PharmacoEconomics 2015, 33, 673.

(19) Rodgers, R. J.; Tschöp, M. H.; Wilding, J. P. H. Anti-Obesity Drugs: Past, Present and Future. Dis. Models \&amp; Mech. 2012, 5, 621.

(20) Van Gaal, L. F.; Broom, J. I.; Enzi, G.; Toplak, H. Efficacy and Tolerability of Orlistat in the Treatment of Obesity: A 6-Month DoseRanging Study. Eur. J. Clin. Pharmacol. 1998, 54, 125.

(21) Yang, M.; Nickels, J. MOGAT2: A New Therapeutic Target for Metabolic Syndrome. Diseases 2015, 3, 176-192.

(22) Denison, H.; Nilsson, C.; Löfgren, L.; Himmelmann, A.; Mårtensson, G.; Knutsson, M.; Al-Shurbaji, A.; Tornqvist, H.; Eriksson, J. W. Diacylglycerol Acyltransferase 1 Inhibition with AZD7687 Alters Lipid Handling and Hormone Secretion in the Gut with Intolerable Side Effects: A Randomized Clinical Trial. Diabetes, Obes. Metab. 2014, 16, 334.

(23) Okawa, M.; Fujii, K.; Ohbuchi, K.; Okumoto, M.; Aragane, K.; Sato, H.; Tamai, Y.; Seo, T.; Itoh, Y.; Yoshimoto, R. Role of MGAT2 and DGAT1 in the Release of Gut Peptides after Triglyceride Ingestion. Biochem. Biophys. Res. Commun. 2009, 390, 377.

(24) Take, K.; Mochida, T.; Maki, T.; Satomi, Y.; Hirayama, M.; Nakakariya, M.; Amano, N.; Adachi, R.; Sato, K.; Kitazaki, T.; Takekawa, S. Pharmacological Inhibition of Monoacylglycerol OAcyltransferase 2 Improves Hyperlipidemia, Obesity, and Diabetes by Change in Intestinal Fat Utilization. PLoS One 2016, 11, No. e0150976.

(25) Zambre, V. P.; Khamkar, S. M.; Gavhane, D. D.; Khedkar, S. C.; Chavan, M. R.; Pandey, M. M.; Sanap, S. B.; Patil, R. B.; Sawant, S. D. Patent Landscape for Discovery of Promising Acyltransferase DGAT and MGAT Inhibitors. Expert Opin. Ther. Pat. 2020, 30, 873.

(26) Park, J. S.; Park, S. B.; Jeon, H.-J.; Jung, W. H.; Kim, H. Y.; Kang, S. K.; Ahn, J. H.; Rhee, S. D.; Kim, K. R.; Kim, K. Y. Optimization of Enzyme Activity Assay for Screening of Acryl CoA:
Monoacylglycerol Acyltransferase 2 Inhibitors. Bull. Korean Chem. Soc. 2015, 36, 1433.

(27) Ma, Z.; Chao, H. J.; Turdi, H.; Hangeland, J. J.; Friends, T.; Kopcho, L. M.; Lawrence, R. M.; Cheng, D. Characterization of Monoacylglycerol Acyltransferase 2 Inhibitors by a Novel Probe in Binding Assays. Anal. Biochem. 2016, 501, 48.

(28) Unuofin, J. O.; Otunola, G. A.; Afolayan, A. J. In Vitro $\alpha$ Amylase, $\alpha$-Glucosidase, Lipase Inhibitory and Cytotoxic Activities of Tuber Extracts of Kedrostis Africana (L.) Cogn. Heliyon 2018, 4, No. e00810.

(29) Shen, Y.; Zheng, L.; Jin, J.; Li, X.; Fu, J.; Wang, M.; Guan, Y.; Song, X. Phytochemical and Biological Characteristics of Mexican Chia Seed Oil. Molecules 2018, 23, 3219.

(30) Kallithraka, S.; Garcia-Viguera, C.; Bridle, P.; Bakker, J. Survey of Solvents for the Extraction of Grape Seed Phenolics. Phytochem. Anal. 1995, 6, 265.

(31) Lee, Y. H.; Choo, C.; Waisundara, V. Y. Determination of the Total Antioxidant Capacity and Quantification of Phenolic Compounds of Different Solvent Extracts of Black Mustard Seeds (Brassica Nigra). Int. J. Food Prop. 2015, 18, 2500.

(32) Lee, J.-G.; Chae, Y.; Shin, Y.; Kim, Y.-J. Chemical Composition and Antioxidant Capacity of Black Pepper Pericarp. Appl. Biol. Chem. 2020, 63, 35.

(33) Harris, L. A. L. S.; Skinner, J. R.; Wolins, N. E. Imaging of Neutral Lipids and Neutral Lipid Associated Proteins. Methods Cell Biol. 2013, 116, 213.

(34) Qiu, B.; Simon, M. BODIPY 493/503 Staining of Neutral Lipid Droplets for Microscopy and Quantification by Flow Cytometry. BioProtocol 2016, 6, 1-6.

(35) Xie, L.; Dai, Z.; Pang, C.; Lin, D.; Zheng, M. Cellular Glucose Metabolism Is Essential for the Reduction of Cell-Impermeable Water-Soluble Tetrazolium (WST) Dyes. Int. J. Biol. Sci. 2018, 14, 1535.

(36) Adachi, R.; Ishii, T.; Matsumoto, S.; Satou, T.; Sakamoto, J.; Kawamoto, T. Discovery of Human Intestinal MGAT Inhibitors Using High-Throughput Mass Spectrometry. SLAS Discovery 2017, 22, 360 .

(37) Bradford, M. A. Rapid and Sensitive Method for the Quantitation of Microgram Quantities of Protein Utilizing the Principle of Protein-Dye Binding. Anal. Biochem. 1976, 72, 248.

(38) Yen, C. L. E.; Stone, S. J.; Cases, S.; Zhou, P.; Farese, R. V. Identification of a Gene Encoding MGAT1, a Monoacylglycerol Acyltransferase. Proc. Natl. Acad. Sci. U.S.A. 2002, 99, 8512.

(39) Swetha, M. P.; Muthukumar, S. P. Characterization of Nutrients, Amino Acids, Polyphenols and Antioxidant Activity of Ridge Gourd (Luffa Acutangula) Peel. J. Food Sci. Technol. 2016, 53, 3122 .

(40) Lee, K. J.; Oh, Y. C.; Cho, W. K.; Ma, J. Y. Antioxidant and Anti-Inflammatory Activity Determination of One Hundred Kinds of Pure Chemical Compounds Using Offline and Online Screening HPLC Assay. Evidence-Based Complementary Altern. Med. 2015, 2015, 165457.

(41) Fernandes, R. P. P.; Trindade, M. A.; Tonin, F. G.; Lima, C. G.; Pugine, S. M. P.; Munekata, P. E. S.; Lorenzo, J. M.; de Melo, M. P. Evaluation of Antioxidant Capacity of 13 Plant Extracts by Three Different Methods: Cluster Analyses Applied for Selection of the Natural Extracts with Higher Antioxidant Capacity to Replace Synthetic Antioxidant in Lamb Burgers. J. Food Sci. Technol. 2016, $53,451$. 